\title{
PENGARUH PEMBELAJARAN PROJECT BASED LEARNING BERINTEGRASIKAN SCIENCE, TECHNOLOGY, ENGINEERING, AND MATHEMATICS (STEM) TERHADAP HASIL BELAJAR GEOGRAFI DI SMA NEGERI 1 GORONTALO
}

\section{INFO ARTIKEL \\ Status artikel: \\ Diterima: 06-09-2021 \\ Disetujui: 28-09-2021 \\ Tersedia online: $29-09-2021$ \\ Kata kunci: \\ STEM; Project Based Learning; Learning Outcomes}

Novia Ayu Lestaria ${ }^{a}$, Sunarty Suly Erakub ${ }^{\mathrm{b}}$, Rusiyah ${ }^{\mathrm{c}}$

abc Universitas Negeri Gorontalo, Jl.Prof. Dr Ing Habibie, Kabupaten Bone Bolango 96119, Indonesia

\section{Penulis korespondensi:}

Novia Ayu Lestari

Pendidikan Geografi, Universitas Negeri

Gorontalo, Gorontalo, Indonesia

Email: ayulestarinovia691@gmail.com

DOI: 10.34312 /jgej.v2i2.11587

Copyright () 2021 The Author(s)

\section{ABSTRACT}

The influence of science, technology, engineering, and mathematics (STEM) Integrend Learning Process on the Learning Outcomes of 1 th Grade Student (An Experimental Research Implementend in SMA 1 State Senior High School if Gorontalo). This study aimed to determine the differences in learning outcomes of student with the implementation of the Ppa-STEM learning model whilw the control class implemented the learning cycle (5E) learning model on the topic of "population planning and Development Dynamis in Indonesia". To achieve these objecives, this research employed experimental design with post-test Control Group Design. Data collection techniques involved learning result test, which was provided towards the sample of research. The sample of the study consisted of two classes; class XIb3 of social science as the control class employed the learning cycle (5E) model. During the hypothesis testing, the homogeneity and normality test of the data was conducted in order to conduct hypothesis testing by using parametric statistics. The data normality test employed a chi-square statistical test of the pair of null hypothesis $\mathrm{H}_{\mathrm{o}}$ and its match $\mathrm{H}_{\mathrm{i}}$ with $\alpha=0,05$ significal rate. The test result showed that $\chi^{2}$ count $<\chi^{2}$ table for the experimental class with 3,449< 11,070 and the control class of $1,023 \leq 9,488$. The result revealed that the two data classes can be normally distributed. Based on the results of normality test data, the average score pg students learning outcomes used the statistical test. The hypothesis test results obtained $t_{\text {count }}>t_{\text {table }}$ which was 6,58 $>2,02$. All in all, the results revealed that there were differences in the learning outcomes of students who used the two aforeentioned learning models

\section{ABSTRAK}

Penelitian ini bertujuan untuk mengetahui hasil belajar peserta didik menggunakan model pembelajaran Project Based Learning yang diintegrasikan dengan Science, Technology, Engineering, And Mathematics pada materi dinamika kependudukan di Indonesia. Metode yang digunakan pada penelitian ini ialah desain posttest Control Group Design. Teknik pengumpulan data melalui tes hasil belajar yang diberikan pada sampel penelitian. Sampel penelitian terdiri atas dua kelas yaitu kelas XIb3 IPS sebagai kelas eksperimen sedangkan XIb5 IPS sebagai kelas kontrol. Pengujian normalitas data menggunakan uji statistic chi-kuadrat untuk pasangan hipotesis $\mathrm{H}_{0}$ dan $\mathrm{H}_{1}$ dengan taraf signifikan $\alpha=0,05$. Hasil pengujian normalitas tes hasil belajar peserta didik menunjukkan bahwa $\chi^{2}$ hitung $<\chi^{2}$ tabel yaitu untuk kelas eksperimen sebesar 3,449< 11,070 dan untuk kelas kontrol sebesar $1,023 \leq 9,488$. Data hasil penelitian ini menunjukkan bahwa kedua kelas tersebut dapat berdistribusi normal berdasarkan hasil pengujian normalitas data. Rata-rata skor hasil belajar peserta didik dengan menggunakan statistic uji $t$ maka hasil pengujian hipotesis didapatkan thitung $>t_{\text {tabel }}$ yaitu $6,58>2,02$. Hasil ini menunjukkan bahwa terdapat perbedaan hasil belajar peserta didik yang menggunakan model pembelajaran Project Based Learning (PjBL) dengan hasil belajar yang menggunakan model pembelajaran Learning Cycle (5E). 


\section{Pendahuluan}

Era disruption pada Abad 21 telah menjadi kenyataan yang harus dihadapi oleh bangsa dan negara Indonesia. Oleh karena itu, institusi pendidikan termasuk sekolah dan perguruan tinggi perlu mampu menumbuhkan generasi berkualitas yang mampu beradaptasi dengan tantangan era disrupsi ini (Oey et al., 2017). Pendidikan dituntut aktif dan inovatif dalam menerapkan strategi pembelajaran. Hal ini untuk memenuhi tuntutan agar peserta didik mempunyai sejumlah keterampilan yang dituntut era abad 21, yaitu mempunyai keterampilan berpikir kritis, kreatif, memiliki kemampuan memecahkan masalah, dan membuat keputusan. Oleh karena itu, pendidik mempunyai kewajiban untuk mempersipkan generasi yang memiliki kemampuan antara lain manusia melek teknologi juga melek pikir, yang mampu "think globally but act locally" pembangunan generasi masa depan merupakan syarat dari upaya pembaharuan pendidikan (Tirtaharja \& Sulo, 2005). Berbagai guru melakukan upaya dan strategi agar materi atau topik mudah dicerna oleh topik pembelajaran, yaitu untuk mencapai tujuan pembelajaran yang telah ditetapkan. Tujuan ini adalah deskripsi dari perilaku yang diharapkan dimiliki oleh subjek belajar yang diharapkan (Asmani \& Ma'mur, 2012).

Penerapan kurikulum kampus merdeka merupakan upaya mengingat persaingan di abad 21 membutuhkan sumber daya manusia yang kompetitif di bidang sains, teknologi, desain teknik dan matematika, maka pemerintah akan mengembangkan pendidikan di Indonesia (Widayanti et al., 2019). STEM Terintegrasi adalah cara untuk membuat pembelajaran lebih terhubung dan relevan dengan siswa (Stohlmann et al., 2012). Pembelajaran sangat diperlukan interaksi positif antara guru dan peserta didik yang menyenangkan, dan tidak membosankan (Otoluwa et al., 2019). Pembelajaran diperlukan adanya suatu pendekatan, pendekatan merupakan titik tolak dalam memandang sesuatu, suatu filsafat atau keyakinan yang tidak selalu mudah membuktikannya (Mulyono, 2016). Bahwa pada dasarnya peserta didik memiliki keterampilan dalam penguasaan konsep dan keterampilan berpikir yang baik, seperti halnya keterampilan berpikir kritis dalam belajar, tetapi terkadang keterampilan tersebut tidak dapat berkembang dengan baik (Yustyan et al., 2015).

STEM adalah pendekatan yang melibatkan speserta didik dalam kegiatan metakognitif Stem memiliki sebuah implementasi di kelas yang menyediakan peluang bagi para peserta didik untuk memahami pentingnya integrasi yang berbeda disiplin dan aplikasinya (Anwari et al., 2015). Hasil belajar merupakan pemahaman dan kemampuan peserta didik yang telah dimiliki setelah mendapatkan pengalaman baru pada pembelajaran. Warsito dalam (Depdiknas, 2006). STEM memberikan arahan pada pendidik agar memberikan proses belajar berbasis proyek serta mengkaitkan beberapa bidang ilmu diantaranya yaitu, teknologi, seni, sains, matematika, dan rekayasa (Zubaidah, 2019). STEM adalah suatu pedagogi yang baru guna merespon apa yang dibutuhkan peserta didik dalam meningkatakan minatnya didunia teknologi, sains, dan matematika (Perignat \& Katz-Buonincontro, 2019).

Project Based Learning berbasis (STEM) juga memberikan tantangan dan motivasi bagi para peserta didik, karena hal tersebut mampu memberikan pola pikir kritis peserta didik, dan mampu meningkatkan keterampilan serta analisis tingkat tinggi dalam berpikir (Afriana et al., 2016). STEM juga telah berhasil menjadikan perancangan dan diskusi sebagai topik pertama di Amerika Serikat dalam beberapa tahun ini karena persaingan negara bergantung dengan tingkat penddikan yang kuat yang mempersiapkan para ilmuan dan insinyur yang inovatif yang akan memberikan inovasi penting untuk ekonomi yang berkembang di era teknologi ini (Suwarma et al., 2015).

Selama implementasi, STEM dapat diintegrasikan dengan model pembelajaran berbasis proyek, pembelajaran berbasis masalah, pembelajaran eksplorasi, dan pembelajaran berbasis pertanyaan (Dewi, 2017; LaForce et al., 2017; Redkar, 2012). Beberapa hasil penelitian menunjukkan bahwa penerapan pendidikan STEM dalam pembelajaran sains sangat diminati karena dapat menumbuhkan keterampilan kognitif, penggunaan teknologi, penggunaan terapan, manipulasi, dan desain (Capraro et al., 2013; White, 2014). Pembelajaran berbasis proyek adalah metode pembelajaran yang berpusat pada siswa dengan dukungan pendidik. Dalam hal ini, siswa memahami melalui pertanyaan-pertanyaan yang dapat dijawab secara emosional dan rasa ingin tahunya (Fernandes et al., 2014).

\section{Metode}

\subsection{Waktu dan Tempat Penelitian}

Penelitian dilaksanakan pada bulan Februari 2020 pada semester genap, dari mulai tahap penyusunan proposal selama 4 bulan hingga pada tahap penelitian sampai pada tahap olah data sekitar kurang lebih 4 
bulan lamanya. Menjadi lokasi penelitian adalah SMA Negeri 1 Gorontalo terletak di Jalan. M.H Thamrin No.8. Kelurahan Ipilo. Kecamatan Kota Timur, Kota Gorontalo.

\subsection{Populasi dan Sampel}

Populasi yang dimaksud penelitian ini ialah seluruh peserta didik kelas XI IPS semester genap SMA Negeri 1 Gorontalo pada tahun ajaran 2020/2021. Adapun sampel pada penelitian yaitu, dua kelas yaitu kelas XIb3 IPS dan kelas XIb5 IPS SMA Negeri 1 Gorontalo, dimana kelas XIb3 IPS jumlahnya 25 sebagai kelas eksperimen dan kelas XIb5 IPS jumlahnya 26 sebagai kelas kontrol. Dengan demikian Sampel keseluruhan berjumlah 51 peserta didik.

\subsection{Variabel Penelitian}

Variabel bebas, pembelajaran berintegrasi Science, Technology, Engineering, and Mathematics (STEM) model PJBL-STEM. Variabel terikat, hasil belajar peserta didik kelas XIb3 dan XIb5 IPS SMA I Gorontalo pada materi dinamika Kependudukan di Indonesia untuk Perencanaan Pembangunan.

\subsection{Jenis dan Desain Eksperimen}

Pada Pretest-Posstest Control Group Design tabel 1 merupakan desain yang membandingkan tes awal dan tes akhir.

Tabel 1. Desain Penelitian

\begin{tabular}{cccc}
\hline Kelompok & Pretest & Treatment/Perlakuan & Post test \\
\hline Eksperimen & $\mathrm{A}_{1}$ & $\mathrm{X}_{1}$ & $\mathrm{~A}_{2}$ \\
\hline Kontrol & $\mathrm{B}_{1}$ & $\mathrm{X}_{2}$ & $\mathrm{~A}_{2}$ \\
\hline
\end{tabular}

\subsection{Teknik Analisis Data}

Untuk menguji data, apakah data hasil penelitian yang diperoleh berdistribusi normal atau tidak berdistribusi normal. Uji normalitas yang digunakan adalah chisquare test (tes kali kuadrat) dengan persamaan sebagai berikut:

\section{Hasil dan Pembahasan}

$$
X_{\text {hitung }}^{2}=\sum \frac{\left(F_{0}-F_{e}\right)}{f e}
$$

Data yang diperoleh pada penelitian ini ialah data yang terkumpul dari tes hasil belajar geografi berupa pretest dan posstest yang dilakukan pada dua kelas yang berbeda, untuk kelas eksperimen dan kelas kontrol. Kelas eksperimen menggunakan pendekatan Science, Technology Engineering, and Mathematics (STEM) model Pembelajaran Project Based Learning (PjBL) pada kelas XIb3 IPS (31 peserta didik), sedangkan kelas kontrol menggunakan pendekatan Science, Technology, Engineering, and Mathematics (STEM) model Learning Cycle (5E) pada kelas XIb5 IPS (30 peserta didik).

\subsection{Data Hasil Dimensi Kognitif Pada Pretest dan Post test}

Sebelum diberikan perlakuan, masing-masing kelas diberikan tes awal (pretest) terlebih dahulu. Hal ini dilakukan untuk melihat sejauh mana pengetahuan awal peserta didik konsep yang akan diajarkan, yakni materi perencanaan dan pembangunan di Indonesia. Nilai rata-rata diperoleh dari penjumlahan skor masingmasing peserta didik kemudian dibagi jumlah keseluruhan peserta didik pada tiap kelas. Dengan kriteria ketuntasan minimal (KKM) yang ditetapkan sekolah untuk mata pelajaran geografi yaitu sebesar 70 dari nilai maksimum 100 . 
Tabel 2. Data hasil Pretest dan Post test

\begin{tabular}{ccccc}
\hline \multirow{2}{*}{ Data } & \multicolumn{2}{c}{ Pretest } & \multicolumn{2}{c}{ Post test } \\
\cline { 2 - 5 } & Eksperimen & Kontrol & Eksperimen & Kontrol \\
\hline $\mathrm{N}$ & 37 & 40 & 37 & 40 \\
\hline Skor Rendah & 10 & 16.7 & 70 & 50 \\
\hline Skor Tinggi & 53.3 & 83.3 & 96.7 & 64.41 \\
\hline Rata-rata & 35.5 & 38.00 & 81.35 & 63.3 \\
\hline Modus & 36.7 & 36.7 & 80 & 63.3 \\
\hline Median & 36.7 & 36.7 & 80 & 7.26 \\
\hline SD & 11.2 & 13.50 & 5.8 & \\
\hline
\end{tabular}

Data pretest tabel 2 menunjukan bahwa pamahamannya peserta didik terhadap materi perencanaan pembangunan di Indonesia pada kedua kelas masih cenderung rendah. Rendahnya hasil belajar peserta didik dirasa wajar dikarenakan memang belum dilakukan kegiatan pembelajaran pada pendekatan Science, Technology Engineering, and Mathematics (STEM) khususnya model PjBL-STEM dan Learning Cycle (5E) pada sekolah tersebut.

\subsection{Deskripsi Data Lembar Kerja Peserta Didik}

aspek psikomotorik peserta didik diberikan lembar kerja peserta didik sesuai pendekatan yang diberikan pada masing-masing kelas. Hasil lembar kerja peserta didik kelas kontrol dan kelas eksperimen disajikan dalam bentuk skor yang didapat pada setiap nomor soal. Hasil tersebut dapat dilihat Tabel 3 dan tabel 4

Tabel 3. Hasil lembar kerja peserta didik kelas eksperimen model PjBL-STEM

\begin{tabular}{|c|c|c|c|c|c|}
\hline \multirow{2}{*}{ Tahap } & \multicolumn{4}{|c|}{ Pertemuan ke } & \multirow[t]{2}{*}{ Rata-rata } \\
\hline & 1 & 2 & 3 & 4 & \\
\hline Observe & 68 & 93,4 & 94 & 70 & 85,13 \\
\hline New idea & 80 & 60 & 95,3 & 68 & 78,43 \\
\hline Innovation & 75,2 & 96,2 & 90 & 68 & 86,8 \\
\hline Creativity & 85,72 & 92,6 & 92,18 & 82 & 90,17 \\
\hline Society & 76 & 60 & 76 & 76 & 0,67 \\
\hline
\end{tabular}

Tabel 4. Hasil lembar kerja peserta didik kelas kontrol model 5E (Bybee)

\begin{tabular}{ccccccc}
\hline Tahap & \multicolumn{9}{c}{ Kelompok } & \multicolumn{2}{c}{ Rata-rata } \\
\cline { 2 - 6 } & 1 & 2 & 3 & 4 & 5 & 57 \\
\hline 1 & 80 & 47 & 72 & 60 & 78 & 71,2 \\
\hline 2 & 54 & 86 & 84 & 82 & 86 & 86,2 \\
\hline 3 & 82 & 85 & 93 & 85 & 84 & 71,2 \\
\hline 4
\end{tabular}

Lembar kerja pada kelas eksperimen dirancang berdasarkan tahapan tertentu yang mendorong peserta didik untuk lebih menggali wawasannya terhadap masalah yang dikemukakan dalam soal serta membutuhkan nalar peserta didik dalam menciptakan gagasan atau ide yang mereka tuliskan dalam sebuah desain atau rancangan penelitian. Berbeda dengan lembar kelas kontrol, pertanyaan dalam soal hanya menguji pemahaman dari pembelajaran terkait dan sedikit analisis dari fakta-fakta tersedia. 


\subsection{Distribusi Frekuensi Kelas Eksperimen dan kelas Kontrol}

a. Kelas Eksperimen

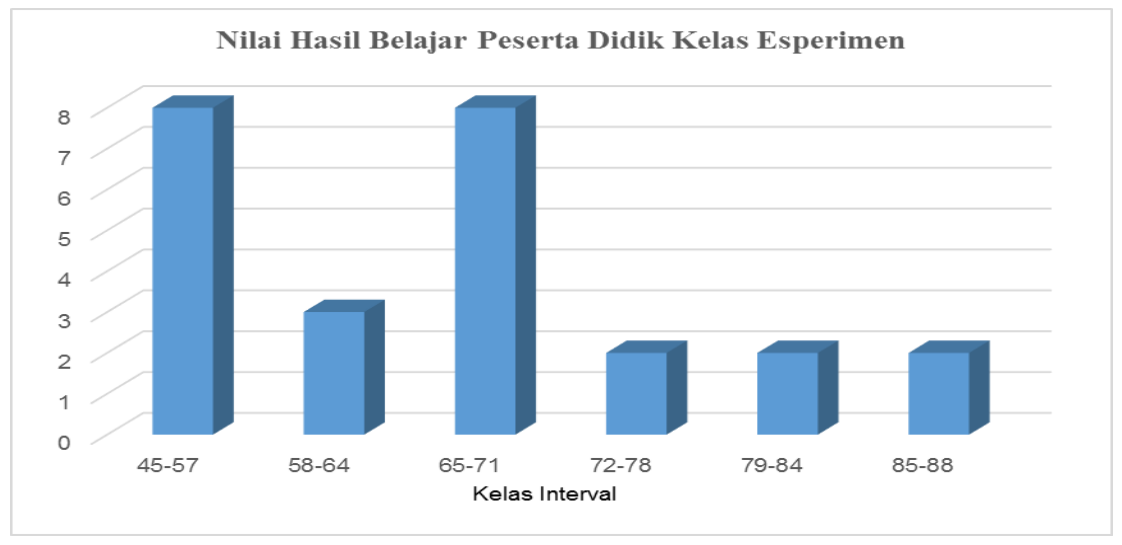

Gambar 1. Grafik Distribusi Frekuensi Kelas Eksperimen

Berdasarkan data pada Grafik Distribusi Frekuensi Kelas Eksperimen gambar 1 yang menunjukan hasil data perhitungan yang telah dilakukan peneliti diketahui terdapat 2 orang peserta didik yang telah memperoleh skor tertinggi pada rentang 85-88, ada sebanyak 2 peserta didik yang menjawab dengan benar dengan rentang 79-84, kemudian 2 orang peserta didik yang menjawab dengan benar dengan rentang 72-78, 8 orang peserta didik yang menjawab dengan benar pada rentang 65-71, 3 orang peserta didik yang menjawab dengan benar pada rentang 58-64, dan 8 orang peserta didik yang menjawab benar pada rentang 45-57.

b. Kelas Kontrol

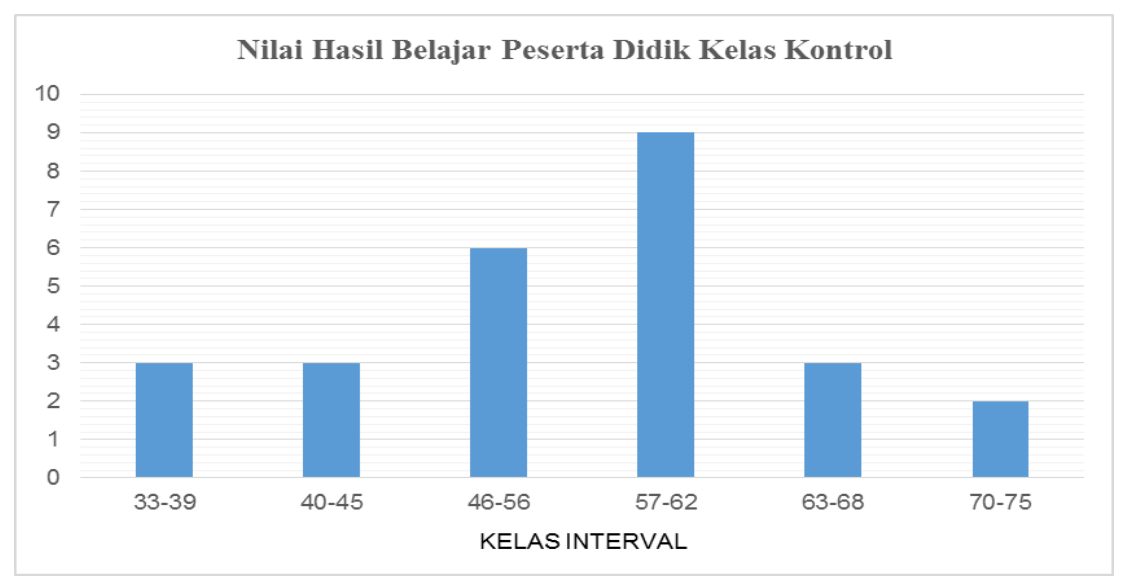

\section{Gambar 2. Grafik Distribusi Frekuensi Kelas Kontrol}

Berdasarkan data gambar 2 diketahui bahwa terdapat 2 orang peserta didik yang memperoleh skor tertinggi pada rentang 70-75, sebanyak 3 peserta didik yang menjawab dengan benar pada rentang 63-68, 9 orang peserta didik yang menjawab dengan benar pada rentang 57-62, 6 orang peserta didik yang telah menjawab benar rentang 46-56, 3 orang peserta didik yang menjawab benar pada rentang 40-45, dan 3 orang peserta didik yang menjawab dengan benar pada rentang 33-39. 


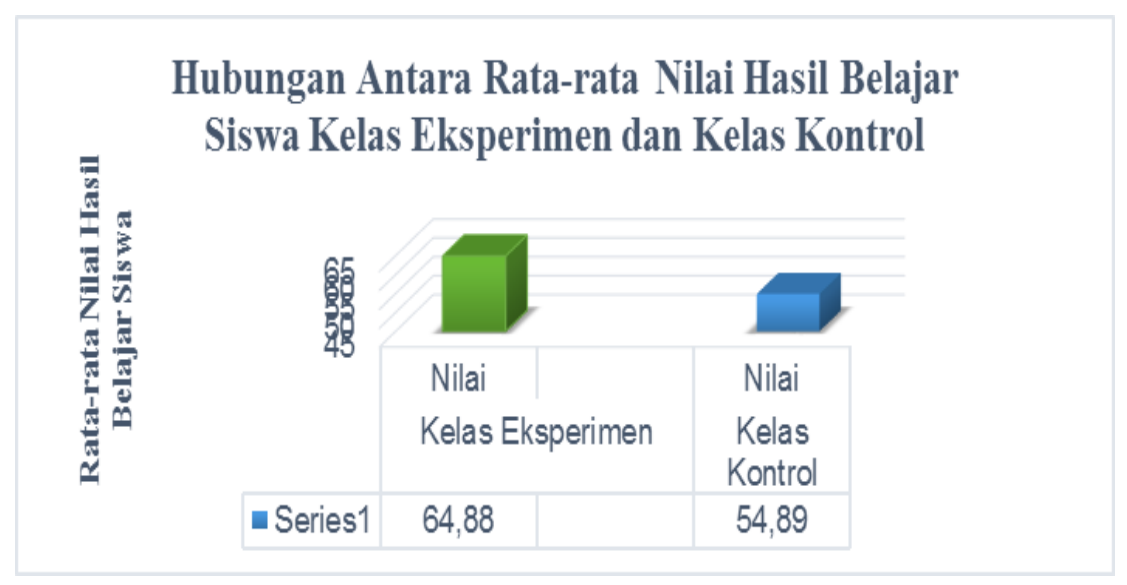

\section{Gambar 3. Grafik Hubungan Antara Rata-rata Nilai Hasil Belajar Peserta Didik Kelas Eksperimen dan Kelas Kontrol}

Berdasarkan gambar 3 rata-rata hasil pembelajaran pada peserta didik kelas eksperimen dan kelas kontrol di atas, dapat dilihat bahwa rata-rata bahwa hasil belajar peserta didik kelas eksperimen sebesar 64,88 sedangkan rata-rata hasil belajar kelas kontrol sebesar 54,89. Disimpulkan rata-rata hasil belajar kelas eksperimen lebih tinggi dari pada kelas kontrol. Hal tersebut dapat terjadi karena pada kelas yang dibelajarkan dengan menggunaan model pembelajaran PjBL-STEM memiliki kelebihan sehingga peserta didik dapat lebih aktif dalam mengikut proses pembelajaran yang disajikan oleh guru atau peneliti dan dapat membangkitkan minat serta keinginan belajar peserta didik sehingga dapat berdampak pada hasil akhir pembelajaran.

Pelaksanaan percobaan penerapan pembelajaran Science, Technology Engineering, and Mathematics (STEM) pada penelitian ini dirasa cukup baik. Hal ini, didukung oleh hasil lembar observasi pencapain aktivitas belajar mengajar dalam kelas. Pada kelas eksperimen aktifitas peserta didik meningkat dari setiap pertemuannya. Pada pertemuan pertama aktifitas peserta didik hanya mencapai rata-rata $50 \%$ hal ini dikarenakan pendekatan yang digunakan masih terasa asing dan membinggungkan bagi peserta didik. Sehingga dinilai pengamat belum maksimal. Setelah pertemuan kedua, ketiga dan keempat terus mengalami peningkatan dikarenakan peserta didik lebih antusias dalam proses belajar dan juga sudah mulai memahami arah dari proses pembelajaran ini. Sedangkan pada kelas kontrol mencapai rata-rata baik karena penggunaan pendekatan yang sama tetapi model yang berbeda yang dirasa ada kemiripan dalam pembelajaran. Namun, mengalami penurunan pada pertemuan akhir menurut pengamat bisa terjadi karena peserta didik merasakan jenuh dengan kegiatan pembelajaran yang hampir sama dengan pembelajaran pendekatan saintifik.

Kerja Science, Technology Engineering, and Mathematics (STEM) membuat peserta didik menggunakan alasan logis dalam menjawab pertanyaan logis dan menjawab pertanyaan kompleks, menginvestigasi isu global, dan mengembangkan solusi untuk tantangan dan masalah dunia. Proses tersebut terdapat dalam tahapan kreatif dalam tahap Science, Technology Engineering, and Mathematics (STEM). Berbeda dengan lembar kerja pada model Learning Cycle (5E) yang hanya mengukur pemahaman peserta didik pada tahap mencoba dengan pertanyaan sederhana yang hanya memerlukan jawaban dari apa yang sudah mereka pelajari. Dalam pengaplikasikan teknologi dalam penyelesaian masalah peserta didik tidak hanya dilatih untuk sekedar mengidentifikasi dan memahami teknologi yang dibutuhkan untuk mengembangkan solusi terhadap masalah atau jawaban atas pertanyaan kompleks. Science, Technology Engineering, and Mathematics (STEM) juga menganalisis batas, resiko, dan dampak dari penggunaan teknologi serta meningkatkan teknologi baru untuk memperluas kemampuan manusia. 


\section{Kesimpulan}

Kesimpulan yang diperoleh dari penelitian ini adalah Science, Technology Engineering, and Mathematics (STEM) melatih kemampuan kreatif peserta didik dalam mengaitkan empat bidang ilmu eksakta sehingga peserta didik memiliki wawasan yang mendalam dan dinamis dalam menyelesaikan terkait materi pembelajaran yang telah diberikan. Pembelajaran Science, Technology Engineering, and Mathematics (STEM) juga mempengaruhi terhadap hasil belajar peserta didik. Uji hipotesis menunjukan perbandingan $t_{\text {hitung }}>t_{\text {tabel }}$ yaitu $6,58>2,02$. Hal tersebut menujukan perbedaan yang signifikan antara hasil belajar kelas eksperimen dengan kelas kontrol. Kelas eksperimen memiliki hasil belajar yang lebih baik dari kelas kontrol.

\section{Ucapan Terima Kasih}

Penulis mengucapkan banyak terima kasih kepada Kepala Sekolah SMA Negeri 1 Gorontalo yang telah memberikan izin melakukan penelitian kepada siswa. Ucapan terima kasih juga yang sebesar-besarnya kepada Bapak dan Ibu Dosen Pembimbing yang telah memberikan dukungan, arahan dan bimbingan sehingga hambatan dan kesulitan dapat peneliti selesaikan dan juga terima kasih untuk kedua orang tua saya dan kaka telah memberikan dukungannya kepada saya baik materil maupun moril.

\section{Referensi}

Afriana, J., Permanasari, A., \& Fitriani, A. (2016). Penerapan project based learning terintegrasi STEM untuk meningkatkan literasi sains siswa ditinjau dari gender. Jurnal Inovasi Pendidikan IPA, 2(2), 202212.

Anwari, I., Yamada, S., Unno, M., Saito, T., Suwarma, I., Mutakinati, L., \& Kumano, Y. (2015). Implementation of Authentic Learning and Assessment through STEM Education Approach to Improve Students' Metacognitive Skills. K-12 STEM Education, 1(3), 123-136.

Asmani, \& Ma'mur, J. (2012). 7 Tips Aplikasi PAKEM (Pembelajaran Aktif, kreatif, Efektif, Dan Menyenangkan). DIVA Press.

Capraro, R. M., Capraro, M., \& Morgan, J. (2013). STEM Project-Based Learning: An Integrated Science, Tchnology, Engineering, and Mathematics (STEM) Approach. Sense Publisher.

Depdiknas. (2006). Bunga Rampai Keberhasilan Guru dalam Pembelajaran (SMA, SMK, dan SLB). Depdiknas.

Dewi, H. R. (2017). Peningkatan Keterampilan Berpikir Kreatif Siswa Melalui Penerapan Inkuiri Terbimbing Berbasis STEM. Prosiding SNPF (Seminar Nasional Pendidikan Fisika), 47-53.

Fernandes, S., Mesquita, D., \& Flores, M. A. (2014). Engaging students in learning: Findings from a studi of project-led education. European Journal of Engineering Education, 39(1), 55-67.

LaForce, M., Noble, E., \& Blackwell, C. (2017). Problem-based learning (PBL) and student interest in STEM careers: The roles of motivation and ability beliefs. Education Sciences, 7(4), 92.

Mulyono, N. (2016). Kurikulum dan Pembelajaran. Rizki Press.

Oey, M., Rahayu, S. I., Amin, M., Effendi, S., Darma, Y., Dartanto, T., \& Aruan, C. D. (2017). Era disrupsi peluang dan tantangan pendidikan tinggi Indonesia. Akademi Ilmu Pengetahuan Indonesia.

Otoluwa, Y., Eraku, S., \& Yusuf, D. (2019). Pengembangan Media Pembelajaran Berbasis Lectora Inspire Yang Diintegrasikan Dengan Camtasia Studio Pada Mata Pelajaran Geografi Materi Sistem Informasi Geografi. JAMBURA GEO EDUCATION JOURNAL, l(1), 01-08. https://doi.org/10.34312/jgej.v1i1.4041

Perignat, E., \& Katz-Buonincontro, J. (2019). STEAM in practice and research: An integrative literature review. Thinking Skills and Creativity, 31, 31-43.

Redkar, S. (2012). Teaching Advanced Vehicle Dynamics Using a Project Based Learning (PBL) Approach. Journal of STEM Education: Innovations \& Research, 13(3).

Stohlmann, M., Moore, T. J., \& Roehrig, G. H. (2012). Considerations for Teaching Integrated STEM Education. Journal of Pre-College Engineering Education Research, 2(1), 28-34.

Suwarma, I., Puji, A., \& Endah, N. (2015). Ballon Powered Car "sebagai media pembelajaran IPA berbasis STEM (Science Technology Engineering Mathematic). Prosinding Simposium Naisonal Inovasi Dan Pembelajaran Sains.

Tirtaharja, U., \& Sulo, S. (2005). Pengantar Pendidikan. Rineka Cipta.

White, D. (2014). What is STEM education and why is it important. Florida Association of Teacher Educators Journal, 1(14), 1-9. 
Widayanti, Abudurrahman, \& Suyatna, A. (2019). Future Physics Learning Materials Based on STEM Education: Analysis of Teachers and Students Perceptions. Journal of Physics: Conference Series, 115. Yustyan, S., Widodo, N., \& Pantiwati, Y. (2015). Peningkatan kemampuan berpikir kritis dengan pembelajaran berbasis scientific approach siswa kelas X SMA Panjura Malang. Jurnal Pendidikan Biologi Indonesia, 1(2).

Zubaidah, S. (2019). STEM (Science, technology, Engineering, Arts, and Mathemtics): Pembelajaran untuk Memperdayakan Keterampilan Abad ke-21. Seminar Nasional Matematika Dan Sains, 1-18. 